\title{
Undergraduates' Views of Assessment in Higher Education: A Study carried out in Portugal
}

\author{
Santos, Patrícia ${ }^{a}$; Pereira, Diana ${ }^{a}$, Mesquita, Diana ${ }^{a}$, Flores, Paulo ${ }^{b}$, Pereira, Rui ${ }^{c}$, \\ Dourado, Nuno ${ }^{b}$ and Flores, Maria Assunção ${ }^{a}$ \\ ${ }^{\mathrm{a}}$ Institute of Education, University of Minho, Portugal. ${ }^{\mathrm{b}}$ School of Engineering, Department, \\ University of Minho, Portugal. ' School of Sciences, University of Minho, Portugal
}

\begin{abstract}
This paper looks at how undergraduates look at assessment in Higher Education. It focuses on their views about assessment practices in five Portuguese public universities. The main purpose is to look at the students' perceptions of assessment in higher education taking into account the assessment methods used, the influence of assessment in their motivation to learn as well as self-regulation of the learning process. Data were collected through questionnaires in five Portuguese Public Universities in different fields of knowledge. An intervention project focused on Assessment for Learning (AfL), with students enrolled at an Engineering programme, in one public university in Portugal, in one course with student-centred methodologies and AfL practices was also carried out and evaluated. Preliminary findings are presented according the categories emerging from the data. Issues of assessment methods, the connection between teaching, learning and assessment as well as the impact of AfL environments on students' perceptions are analysed. Implications of the findings for assessment, teaching and learning process are discussed.
\end{abstract}

Keywords: assessment; undergraduates; higher education; teaching and learning. 


\section{Introduction}

The assessment of the students' learning has been subject to discussion and debate (Sambell et al., 1997; Black \& Wiliam, 1998; Struyven et al., 2005; Pereira et al., 2016). Different perspectives suggest that a shift in the assessment paradigm has occurred, based on the transition from an instructional paradigm to a learning paradigm (Barr \& Tagg, 1995), from a summative 'testing culture' to an integrated 'assessment culture' (Birenbaum, 1997), or, in other words, from a teacher-centred approach to a learner-centred approach (Huba \& Freed, 2000; Kahl \& Venette, 2010).

After the implementation of the Bologna Process, the renewed framework in the curricula has brought about changes with implications for teaching, learning and assessment methodologies. This "new" educational paradigm recognises the key role of students in their learning process based on autonomy, shared work and project-based work (Flores \& Veiga Simão, 2007). In this context, the need for developing Assessment for Learning (AfL) approaches in higher education has been identified (McDowell et al., 2011). As Swaffield (2011, p. 441) argues, AfL is a teaching and learning process and the main concern is "with the here and now of learning". Literature has shown that AfL practices stimulate students' engagement in a more active way, providing them with more positive formative experiences, such as: greater teacher support, flexible curricular design, dialogue opportunities, peer learning and research opportunities (Black, Harrison, Lee, Marshall, \& Wiliam, 2005; McDowell et al., 2011). The development and assessment of these practices implies the adoption of a wide array of assessment methods and fewer tests; feedback to report students' strengths and weaknesses; opportunities to overcome weaknesses, to work in a collaboratively way and to carry out peer or self-assessment; sharing with students the goals of learning and the use of assessments tasks that enhance creativity and understanding rather than memorisation of knowledge (Carless, 2005).

The aim of this paper is to analyse assessment practices in Portuguese higher education settings from the perspective of undergraduates in five Portuguese public universities.

The main purpose is to look at the students' conceptions of assessment in higher education taking into account the assessment methods used, the influence of assessment in their motivation to learn as well as self-regulation of the learning process. Although there are studies focusing on students' conceptions of assessment and their impact on learning (Brown \& Hirschfeld, 2008; Fletcher et al., 2012; Gibbs \& Simpson, 2004) more needs to be done in regard to students' beliefs related to assessment practices, as well as the relationship between their beliefs and the processes of teaching and learning (Brown \& Hirschfeld, 2008). As Biggs (2003) suggests, the ways in which students see assessment will affect their involvement in the learning process. In Biggs' perspective, while in the assessment process cycle, teachers first see the objectives, learning outcomes and learning 
activities and only then look at assessment, students see assessment first of all and only afterwards look at learning activities and the outcomes. Furthermore, earlier literature suggests that the ideas that students associate with assessment are related to their area of knowledge as well as the assessment methods used by their teachers (Pereira, Niklasson, \& Flores, 2016; Pereira, Barros, \& Flores, in press). In other words, assessment influences, either negatively or positively, student learning and may be seen as an incentive for study and for improved performance (Watering, Gijbels, \& Dochy, 2008; Biggs, 2003; Brown \& Knight, 1994; Brown, Bull, \& Pendlebury, 1997; Boud \& Falchikov, 2007).

MacLellan (2001) also concluded that students do not take advantage of assessment to improve their learning and, consequently, have an underdeveloped conception of what assessment is. In addition, "students who conceive assessment as a means of taking responsibility for their learning will demonstrate increased educational outcomes" (Brown \& Hirschfeld, 2008, p. 3).

\section{Method}

This paper draws upon a wider piece of research within the context of a project entitled "Assessment in Higher Education: the potential of alternative methods" funded by the Portuguese Foundation for Science and Technology - (PTDC/MHCCED/2703/2014).

The study is at an early stage and aims to identify and contrast practices and conceptions of assessment in five Portuguese public universities from the perspectives of students through the administration of a questionnaire. The participants are undergraduate students attending the $1^{\text {st }}, 2^{\text {nd }}$ and $3^{\text {rd }}$ year in different areas of knowledge in 5 Portuguese Public Universities. In this study the four scientific fields of research identified at the Portuguese Foundation for Science and Technology were used: Hard Sciences (HS), Social Sciences (SS), Health and Medical Sciences (HMS) and Engineering (E). Different programmes were selected in each field: HS: (Mathematics, Physics and Optometry); SS: (Economics, Law, Education, Basic Education and Psychology); HMS: (Medicine and Nursing) and E: (Biological Engineering, Biomedical Engineering, Civil Engineering, Industrial Management and Engineering and Mechanical Engineering). The questionnaire was administered to the students in person in one of the classes with the permission of the teacher. A research protocol was sent to each university and department as well as to the Dean of each Faculty in order to request permission to conduct the study. Data were analysed through SPSS. Data reported in this paper were also collected through the development of an intervention project focused on AfL, with students enrolled at an Engineering programme, in one public university in Portugal, in one course with student-centred methodologies and AfL practices. The selection of Engineering was associated with the high rate of students' failure and dropout. In total, 70 students participated in this phase where monitoring strategies of teaching, 
learning and assessment and an AfL questionnaire were applied. The study developed was approved by the UMinho Ethics Committee. Data were analysed through SPSS and through content analysis.

\section{Findings}

Preliminary findings suggest that in the students' perspective assessment practices used by university teachers may have an impact on their performance and attitudes towards learning and assessment. Furthermore, students claim that assessment is more effective when it allows the development of both technical and soft skills and when it relates to a real practice in a real context or situation having a positive impact on the quality of learning. Students also perceive assessment as more effective when it promotes deep learning. The participants also associated assessment with neutral ideas such as tests or exams and grades, or positive ideas such as learning or verification of knowledge. Nevertheless, the negative associations such as anxiety or fear have also some of the higher means.

Findings from the intervention project provide an analysis of the implications and potential of AfL in the teaching and learning process. Findings also look at the impact of AfL on students' perceptions about assessment of their learning. According to students' perspectives, assessment in AfL environments tends to be demanding, continuous, fair, well-adjusted and different from usual. Also, students highlight positive aspects related to AfL approaches, such as: development of technical and transversal competencies, tutoring, creativity development, practical component, autonomy, team work, teachers' support, active teaching methodologies and problem-based work. By contrast, time management and articulation of different topics were identified by students as the main difficulties in their learning process. Students also pointed out strategies used to overcome difficulties in the learning process, such as: internet research and tutorials, teachers' support, support and peer learning.

\section{Conclusions}

The perceptions of students, as key participants in the educational process, have enabled to know the aspects related to the assessment process and its implications for learning and teaching. Although results are preliminary, it is posible to state that the impact that assessment has on teaching and learning, it also impacts the future life of the students, because through it certain type of skills required in professional contexts are developed and improved. Accordingly, when students enter into the labour market they can put into practice all these skills developed through the assessment methods. Furthermore, self- and peer assessment are to be preferred in higher education, since these methods enhance learning and develop student assessment skills. Therefore, assessment influences the 
process of teaching, learning and students' performance on the professional future. The findings have implications for (re)thinking the practices of assessment in Higher Education, particularly in regard to the usefulness and relevance of peer and self-assessment as well as for the connection between assessment methods and views of teaching and learning from the part of both students and university teachers.

Note: This work is funded by FEDER Funds through the COMPETE Programme and by National Funds through the FCT - Fundação para a Ciência e a Tecnologia (National Foundation for Science and Technology) within the context of the project "Assessment in Higher Education: the potential of alternative methods" (PTDC/MHCCED/2703/2014).

\section{References}

Barr, R., \& Tagg, J. (1995). From teaching to learning: a new paradigm for undergraduate education. Change, 27(6), 12-25.

Biggs, J. (2003). Teaching for Quality Learning at University. Buckingham: SHRE and Open University Press.

Birenbaum, M. (1997). Assessment preferences and their relationship to learning strategies and orientations. Higher Education, 33(1), 71-84.

Black, P., Harrison, C., Lee, C., Marshall, B., \& Wiliam, D. (2005). Assessment for Learning. Putting it into practice. England: Open University Press.

Black, P., \& Wiliam, D. (1998). Assessment and Classroom Learning. Assessment in Education: Principles, Policy \& Practice, 5(1), 7-74.

Boud, D., \& Falchikov, N. (2007). Rethinking assessment in higher education: learning for the long term. Routledge: New York.

Brown, G., Bull, J., \& Pendlebury, M. (1997). Assessing student learning in higher education. London: Routledge.

Brown, G., \& Hirschfeld, G. (2008). Students' conceptions of assessment: links to outcomes. Assessment in Education: Principles, Policy \& Practice, 15(1), 3-17.

Brown, S., \& Knight, P. (1994). Assessing learners in higher education. London: Kogan Page.

Carless, D. (2005). Prospects for the implementation of assessment for learning. Assessment in Education: Principles, Policy \& Practice, 12(1), 39-54.

Fletcher, R., Meyer, L., Anderson, H., Johnston, P., \& Rees, M. (2012). Faculty and Students Conceptions of Assessment in Higher Education. Higher Education, 64 (1), 119- 133.

Flores, M. A., \& Veiga Simão, A. M. (2007). Competências desenvolvidas no contexto do Ensino Superior: a perspetiva dos diplomados. In V Jornadas de Redes de Investigación en Docencia Universitaria, 4-5 junho 2007. Alicante. 
MacLellan, E. (2001). Assessment for Learning: The differing perceptions of tutors and students. Assessment \& Evaluation in Higher Education, 26(4), 307-318.

McDowell, L., Wakelin, D., Montgomery, C., \& King, S. (2011). Does assessment for learning make a difference? The development of a questionnaire to explore the student response. Assessment \& Evaluation in Higher Education, 36(7), 749-765.

Gibbs, G., \& Simpson, C. (2004). Conditions under which assessment supports students'learning. Learning and Teaching in Higher Education, 1, 3-31. Retrieved from

http://www.open.ac.uk/fast/pdfs/Gibbs\%20and\%20Simpson\%202004-05.pdf.

Huba, M.E., \& Freed, J. (2000). Learner-centered Assessment on College Campuses: Shifting the Focus from Teaching to Learning. Boston, MA: Allyn and Bacon.

Kahl, D., \& Venette, S. (2010). To Lecture or Let Go: A Comparative Analysis of Student Speech Outlines from Teacher-Centered and Learner-Centered Classrooms. Communication Teacher, 24(3), 178-186.

Pereira, D., Flores, M., \& Barros, A. (in press). Perceptions of Portuguese undergraduate students about assessment: A study in five public universities. Educational Studies.

Pereira, D., Flores, M., \& Niklasson, L. (2016). Assessment revisited: a review of research in Assessment and Evaluation in Higher Education. Assessment \& Evaluation in Higher Education, 41(7), 1008-1032.

Pereira, D., Niklasson, L., \& Flores, M.A. (2016). Students' perceptions of assessment: a comparative analysis between Portugal and Sweden. Higher Education. doi:10.1007/s10734-016-0005-0.

Sambell, K., McDowell, L., \& Brown, S. (1997). But is it fair?: an exploratory study of student perceptions of the consequential validity of assessment. Studies in Educational Evaluation, 23(4), 349-371.

Struyven, K., Dochy, F., \& Janssens, S. (2005). Students' perceptions about evaluation and assessment in higher education: a review. Assessment \& Evaluation in Higher Education, 30(4), 331-347.

Swaffield, S. (2011). Getting to the heart of authentic assessment for learning. Assessment in Education: Principles, Policy \& Practice, 18, 433-449.

Watering, G., Gijbels, D., Dochy, F., \& Rijt, J. (2008). Students' assessment preferences, perceptions of assessment and their relationships to study results. Higher Education, 56(6), 645-658. 